\title{
Factors related to recurrence of idiopathic granulomatous mastitis: what do we learn from a multicentre study?
}

\author{
Erdal Uysal (1),* Atilla Soran† and Efe Sezgin,‡ Granulomatous Mastitis Study Group \\ *Department of General Surgery, Sanko University School of Medicine, Gaziantep, Turkey \\ tDepartment of Breast Surgery, Magee-Womens Hospital of UPMC, Pittsburgh, Pennsylvania, USA and \\ ‡Laboratory of Nutrigenomics and Epidemiology, Department of Food Engineering, İzmir İnstitute of Technology, Izmir, Turkey
}

\section{Key words}

granulomatous, idiopathic, mastitis, recurrence, risk factors.

\section{Correspondence}

Dr Erdal Uysal, Department of General Surgery, Sanko University School of Medicine, Incilipınar Mahallesi Ali Fuat Cebesoy, Bulvarı No: 45, 27090 Sehitkamil, Gaziantep, Turkey.

Email: drerdaluysal@hotmail.com

\section{E. Uysal MD; A. Soran MD, MPH, FACS; E. Sezgin $\mathrm{PhD}$.}

The members of the Granulomatous Mastitis Study Group are: Halil Turkan, Sadullah Girgin, Hasan Karanlik, Neslihan Cabioglu, Zafer Utkan, Göktürk Maralcan, Ayfer Kamalı Polat, Emine Yeliz Ersoy, Alper Akcan, Kenan Cetin, Oktay Celik, Aykut Soyder, Cihangir Ozaslan, Deniz Boler, Zafer Canturk, Fatih Aydogan, Vahit Ozmen, Turgay Simsek, Serkan Turel, Serdar Ozbas, Abut Kebudi, Ugur Deveci, Hasan Bakir, Orhan Ahmet Gurer, Avni Gokalp, Sehsuvar Gokgöz, Mehmet Velidedeoglu and Cihan Uras.

Accepted for publication 20 May 2017.

doi: 10.1111/ans.14115

\begin{abstract}
Background: Idiopathic granulomatous mastitis (IGM) is a rare chronic inflammatory disease of the breast with unknown aetiology. Its treatment is controversial and the recurrence rate is high. The objectives of this study were to examine the demographic, sociocultural and clinical characteristics observed among a large cohort of IGM patients from Turkey and to identify factors related to the recurrence of IGM.

Methods: The study was designed as a multicentre retrospective study including 22 breast centres in Turkey. A total of 720 IGM patients are included in the study. Patient data were obtained from the patient's files and electronic records based on the study protocol. Patients' demographic, clinical, radiological, treatment and recurrence of IGM related characteristics were recorded.

Results: Our results revealed a statistically significant association between IGM recurrence and history of pregnancy, breastfeeding, breast infection and smoking $(P<0.05)$. Having a chronic systematic disease, oral contraceptive, analgesic and herbal medicine consumptions, treatment choice, education, place of birth and current residence were not found to be associated with IGM recurrence $(P>0.05)$.

Conclusion: Our findings show that history of pregnancy, breastfeeding, breast infection and smoking were the risk factors for IGM recurrence. As current treatment methods did not affect IGM recurrence, recurrence-related factors, such as breast infection and smoking, should be considered to eliminate while focusing on less invasive local treatment research.
\end{abstract}

\section{Introduction}

Idiopathic granulomatous mastitis (IGM) is a rare chronic inflammatory disease of the breast. It was first defined by Kessler and Wolloch in $1972 .{ }^{1}$ It typically affects young women between 17 and 42 years of age within the reproductive and post-child-bearing period. IGM comprises $24 \%$ of all inflammatory diseases of the breast. $^{2}$

The annual prevalence and incidence of IGM have been reported as 2.4 per 100000 women and $0.37 \%$, respectively. ${ }^{3,4}$ Although its prevalence in Turkey has not been clearly established, it is thought to be higher than in the USA. ${ }^{5}$

Although IGM is a benign disease, it mimics breast cancer, both clinically and radiologically. ${ }^{6}$ As IGM has the same radiological characteristics with breast cancer, dilemmas are observed in the diagnosis. ${ }^{7}$ Precise diagnosis may only be confirmed histopathologically in IGM. ${ }^{8,9}$

The treatment of IGM is still a debate. Currently, there is no universally accepted treatment strategy. Local and systemic corticosteroids and antibiotics are the most frequently used agents in the medical treatment. However, successful results have been reported with agents, such as methotrexate, azathioprine, glucocorticoids, bromocriptine and colchicine. ${ }^{10-12}$ Surgical treatment of IGM includes abscess drainage, local and wide excisions, or mastectomy. Better outcomes have been reported with steroid addition to the surgical treatment. ${ }^{13}$

The aetiology of IGM is not fully understood. However, autoimmune diseases, hormone irregularities, local immune response to 
trauma, local irritants, undetected organisms, viruses, hyperprolactinemia, diabetes, $\alpha$-1-antitrypsin deficiency, smoking, ductal ectasis and oral contraceptive use have been blamed as the aetiology. ${ }^{14}$ Additionally, sarcoidosis, tuberculosis, foreign substances and corynebacterial infections have been blamed for the aetiology. ${ }^{15}$

Recurrence may be observed despite broad surgical excision in IGM. The IGM recurrence rate varies between $5 \%$ and $50 \%$ according to the literature. ${ }^{16-18}$ Post-excision recurrence may be as high as $50 \% .^{5}$ It is important to know the factors affecting recurrence as much as the aetiological factors in the fight against IGM. Analysing the effects of demographic and clinical characteristics along with the aetiological factors on the IGM recurrence may contribute to the decrease in post-treatment recurrence. Therefore, determination of IGM-related aetiological, clinical and epidemiological factors is required. Furthermore, knowing the relationship between these factors and the recurrence may increase the success rates of the treatment. Although the aetiological, epidemiological and clinical characteristics have been evaluated in previous studies, the effects of these factors on the IGM recurrence have been poorly analysed. Furthermore, the sample sizes of these studies were limited, as IGM is a rare disease. Although IGM is a chronic and recurrent disease, there is not much knowledge regarding the IGM recurrence and the relationship of the chosen initial treatment. The objectives of this study were to examine the demographic, sociocultural and clinical characteristics observed among a large cohort of IGM patients from Turkey and to identify factors related to the recurrence of IGM.

\section{Materials and methods}

Our study was designed as a multicentric retrospective study, involving 22 breast centres in Turkey. The data of 720 patients who had the treatment of IGM between January 2011 and March 2016 were included in the study. Patient data were retrospectively obtained by recording the data in patients' files and electronic records based on the protocol created initially for this study. Patients' demographic, clinical, radiological, treatment and recurrence of IGM-related characteristics were recorded. Only the patients who were histopathologically diagnosed with IGM were included in this study. Exclusion criteria included male patients, patients with breast carcinoma coexisted with IGM and non-IGM patients. Patients with tuberculous mastitis were not included in the study. History of pulmonary tuberculosis, evidence of histologically tuberculous mastitis, positive staining with Ziehl-Neelsen or acid-fast or positive tissue cultures and chest X-ray findings consistent with previous tuberculosis findings with positive tuberculin test were excluded in this study. The return of a sign, symptom or disease after a remission was accepted as recurrence. While there were no co-morbidities in 631 patients, various co-morbidities were seen in 89 patients. The definition of a city is a place with a population more than 100000 habitants and has better life conditions with a better healthcare accessibility; town and village have less population with a limited source of healthcare facilities. Previously diagnosed diseases were defined as chronic diseases, such as hypertension, autoimmune disease and diabetes, and patients were under the appropriate care. This study is registered at Clinicaltrials.gov by the number ID NCT02667132.

\section{Statistical analysis}

Continuous and categorical variable differences between the recurrence and no recurrence groups were analysed by $t$-test and chisquare test, respectively. $P$-values $<0.05$ were considered as statistically significant. All statistical analyses were conducted by SAS/STAT version 9.3 (SAS Institute, Inc, Cary, NC, USA).

\section{Results}

A total of 720 IGM patients are included in the study mostly residing in a city. Patient characteristics enrolled in the study are shown in Table 1 . The median age was 36 years (32-42). Median follow-up was $16(8,33)$ months. A great majority of patients reported having given birth and breastfeed. A quarter of the patients had a history of smoking; however, the majority of them did not have any chronic diseases and chronic medication use. Breast infection (30\%) was more common than systemic infection $(11 \%)$ or lactation mastitis $(18 \%)$. The most common symptom was a mass with other symptoms in the breast in $83 \%(n=587)$ of patients, but the minority $(7 \%, n=50)$ of patients had only erythema or fistula (Table 2). On physical examination, $75 \%$ of women had palpable mass $(n=538)$. Our findings showed that IGM often located at upper left quadrant $(28 \%, n=202)$ and only $5 \%$ of the cases were bilateral (Table 2). While $36 \%$ $(n=258)$ of patients received only medical treatment, $8 \%(n=60)$

Table 1 Patient characteristics enrolled in the study

\begin{tabular}{|c|c|c|}
\hline & Percentage & $\begin{array}{c}n \text { (total } \\
\text { patients, } n=720 \text { ) }\end{array}$ \\
\hline Median age $(25 \%, 75 \%)$ & & $36(32,42)$ \\
\hline $\begin{array}{l}\text { Median follow-up (months) } \\
\quad(25 \%, 75 \%)\end{array}$ & & $16(8,33)$ \\
\hline \multicolumn{3}{|l|}{ Patient's place of residence } \\
\hline City & 88 & 626 \\
\hline Town & 9 & 66 \\
\hline Village & 3 & 21 \\
\hline \multicolumn{3}{|l|}{ Education } \\
\hline Primary school & 42 & 257 \\
\hline High school & 36 & 218 \\
\hline University & 12 & 76 \\
\hline None & 10 & 58 \\
\hline Ever given birth & 92 & 662 \\
\hline Ever breast fed & 85 & 612 \\
\hline Oral contraceptive & 13 & 90 \\
\hline Smoking & 24 & 172 \\
\hline \multicolumn{3}{|l|}{ Chronic diseases } \\
\hline None & 88 & 632 \\
\hline Hypertension & 4 & 29 \\
\hline Autoimmune disease & 3 & 21 \\
\hline Other & 3 & 21 \\
\hline Diabetes & 2 & 14 \\
\hline Coronary artery disease & 0.4 & 3 \\
\hline \multicolumn{3}{|l|}{ Infection } \\
\hline Breast infection & 30 & 216 \\
\hline Lactation mastitis & 18 & 130 \\
\hline $\begin{array}{l}\text { Systemic bacterial infection } \\
\text { history }\end{array}$ & 11 & 81 \\
\hline \multicolumn{3}{|l|}{ Medication use } \\
\hline None & 85 & 613 \\
\hline Others & 10 & 71 \\
\hline Pain medicine & 4 & 30 \\
\hline Herbal medicine & 1 & 6 \\
\hline
\end{tabular}

Systemic bacterial infection: bronchopneumonia, urinary system infections and puerperal infections. 
Table 2 Symptom and physical examination, and lesion localization

\begin{tabular}{|c|c|c|}
\hline & Percentage & $\begin{array}{c}n \text { (total } \\
\text { patients, } n=720 \text { ) }\end{array}$ \\
\hline \multicolumn{3}{|l|}{ Symptom } \\
\hline Mass & 83 & 587 \\
\hline Pain & 10 & 72 \\
\hline Other & 7 & 50 \\
\hline \multicolumn{3}{|l|}{ Physical examination } \\
\hline Palpable mass & 75 & 538 \\
\hline Abscess & 42 & 302 \\
\hline Fistula & 30 & 215 \\
\hline $\begin{array}{c}\text { Axillary palpable } \\
\text { lymph node }\end{array}$ & 7 & 50 \\
\hline \multicolumn{3}{|l|}{ Lesion localization } \\
\hline Left upper quadrant & 28 & 202 \\
\hline Left lower quadrant & 9 & 67 \\
\hline Right upper quadrant & 23 & 166 \\
\hline Right lower quadrant & 12 & 83 \\
\hline Central & 13 & 90 \\
\hline Multiple quadrants & 15 & 112 \\
\hline
\end{tabular}

received only surgical treatment. The combination of surgical and medical treatment was administered to the majority of the patients $(56 \%, n=398)$. The most frequent surgical treatment was wide local excision with $69 \%(n=323)$ followed by abscess drainage in $29 \%$ $(n=137)$ and mastectomy in $1.3 \%(n=6)$ (Table 3). Oral steroids were the first choice for medical treatment $(39 \%, n=253)$ followed by antibiotics in $37 \%(n=240)$ and the combination of steroid and antibiotics were given to $13 \%(n=87)$ of the patients. Methotrexate was given to only $1 \%(n=5)$ of the patients. Ultrasound, mammography and magnetic resonance imaging were used in $95 \%(n=85){ }^{6}$

Table 3 Granulomatous mastitis-related clinical characteristics

\begin{tabular}{|c|c|c|}
\hline & Percentage & $\begin{array}{c}n \text { (total } \\
\text { patients, } n=720 \text { ) }\end{array}$ \\
\hline Unilateral & 93 & 671 \\
\hline Bilateral & 7 & 49 \\
\hline \multicolumn{3}{|l|}{ Pathological diagnosis } \\
\hline Tru-cut & 62 & 437 \\
\hline Post-operative pathology & 20 & 142 \\
\hline Excisional & 7 & 52 \\
\hline Incisional & 7 & 48 \\
\hline FNAB & 4 & 30 \\
\hline \multicolumn{3}{|l|}{ Treatment } \\
\hline Only medical & 36 & 258 \\
\hline Surgery then medical & 33 & 234 \\
\hline Medical then surgery & 23 & 164 \\
\hline Only surgery & 8 & 60 \\
\hline \multicolumn{3}{|l|}{ Medical treatment } \\
\hline Antibiotic & 37 & 240 \\
\hline Steroid & 39 & 253 \\
\hline Steroid + antibiotic & 13 & 87 \\
\hline Others & 9 & 57 \\
\hline Antituberculosis therapy & 2 & 12 \\
\hline Methotrexate & 1 & 5 \\
\hline \multicolumn{3}{|l|}{ Surgical treatment } \\
\hline Wide local excision & 69 & 323 \\
\hline Only abscess drainage & 29 & 137 \\
\hline Mastectomy & 1.3 & 6 \\
\hline Recurrence & 17 & 122 \\
\hline $\begin{array}{l}\text { Relapse after recurrence } \\
\text { therapy }\end{array}$ & 3 & 22 \\
\hline
\end{tabular}

$36 \%(n=258)$ and $32 \%(n=228)$ of the patients, respectively, and $67 \%(n=300)$ of cases were scored as BIRADS 3 .

The overall incidence rate of the first recurrence was $17 \%$ $(n=122)$. IGM re-recurrence after treatment of patients was $3 \%(n=22)$. Our results revealed that there are statistically significant associations between IGM recurrence and pregnancy, breastfeeding, smoking and history of breast infection $(P<0.05)$. On the other hand, using an oral contraceptive, chronic medication use, receiving various IGM treatment methods, education, chronic diseases, place of birth and place of current residence were not found to be associated with IGM recurrence $(P>0.05)$ (Table 4$)$.

\section{Discussion}

IGM is a rare inflammatory disease of the breast. It generally affects young women in their reproductive ages. ${ }^{1}$ The pathophysiology of IGM is not clearly understood. However, the onset of some chemical reactions with oral contraceptive intake, infectious processes and autoimmunity are considered to be involved. ${ }^{19}$

Table 4 Comparison of demographic and clinical characteristics, and treatment regimens between patient with and without IGM recurrence

\begin{tabular}{|c|c|c|c|}
\hline \multirow[t]{2}{*}{ Demographic } & \multicolumn{2}{|c|}{ IGM recurrence } & \multirow[t]{2}{*}{$P$-value } \\
\hline & $\begin{array}{c}\text { No } \\
(n=598)\end{array}$ & $\begin{array}{c}\text { Yes } \\
(n=122)\end{array}$ & \\
\hline Median age $(25 \%, 75 \%)$ & $36(32,42)$ & $35(32,41)$ & 0.42 \\
\hline Patient's place of residence, $\%(n)$ & & & 0.11 \\
\hline Village & $3(20)$ & $1(1)$ & \\
\hline Town & $9(51)$ & $13(15)$ & \\
\hline City & $88(523)$ & 87 (103) & \\
\hline Education, \% (n) & & & 0.83 \\
\hline Primary school & 42 (209) & $45(48)$ & \\
\hline High school & $36(181)$ & 35 (37) & \\
\hline University & $9(47)$ & $10(11)$ & \\
\hline None & $13(65)$ & $10(11)$ & \\
\hline \multicolumn{4}{|l|}{ Patient characteristics, \% (n) } \\
\hline Pregnancy & $91(542)$ & $98(120)$ & 0.0008 \\
\hline Breast feeding & $84(501)$ & $91(111)$ & 0.03 \\
\hline Smoking & $22(132)$ & $33(40)$ & 0.01 \\
\hline Oral contraceptive & $12(74)$ & $13(16)$ & 0.80 \\
\hline Medication use, \% (n) & & & 0.7 \\
\hline None & $85(508)$ & 86 (105) & \\
\hline Others & $10(58)$ & $11(13)$ & \\
\hline Pain medicine & $5(27)$ & $2(3)$ & \\
\hline Herbal medicine & $1(5)$ & $1(1)$ & \\
\hline $\begin{array}{l}\text { Systemic bacterial infection } \\
\text { history, \% (n) }\end{array}$ & $12(74)$ & $6(7)$ & 0.02 \\
\hline Breast infection, \% (n) & $28(170)$ & $38(46)$ & 0.045 \\
\hline Chronic diseases, \% ( $n)$ & & & 0.52 \\
\hline None & $88(527)$ & 85 (104) & \\
\hline Hypertension & $4(24)$ & $4(5)$ & \\
\hline Autoimmune disease & $3(15)$ & $5(6)$ & \\
\hline Other & $3(18)$ & $2(3)$ & \\
\hline Diabetes & $1.7(10)$ & $3(4)$ & \\
\hline Coronary artery disease & $0.5(3)$ & $0(0)$ & \\
\hline Treatment, \% (n) & & & 0.14 \\
\hline Only medical & $37(221)$ & 30 (37) & 0.14 \\
\hline Only surgery & $8(48)$ & $10(12)$ & 0.53 \\
\hline Medical then surgery & $22(130)$ & $28(34)$ & 0.15 \\
\hline Surgery then medical & 33 (195) & 32 (39) & 0.85 \\
\hline
\end{tabular}


Although the possible aetiological factors of IGM have not been certainly defined, some factors are believed to be effective, which include autoimmune diseases, undetected microorganisms, hyperprolactinaemia, diabetes and oral contraceptive use. ${ }^{14}$ However, the exact factors have not been established yet. In addition to the clinical characteristics of the disease, defining the relation of epidemiological factors with IGM may be important in the prevention.

The studies of Aghajanzadeh et al. $(n=206),{ }^{18}$ Al-Khaffaf $e t$ al . $(n=133),{ }^{20}$ Korkut et al. $(n=93),{ }^{21}$ Akcan et al. $(n=74)^{13}$ and Karanlik et al. $(n=60)^{17}$ with rather large series in the literature were those in which some demographic characteristics could be related to IGM. However, as far as our knowledge, our study has the largest number with 720 IGM patients comparing the effects of epidemiological-demographic-clinical factors on recurrence.

Various studies have reported an effect of ethnic origin and geographic region on the IGM prevalence. ${ }^{3,22}$ The prevalence of IGM has been reported to be high in Turkey, Asia, and Far Eastern countries. ${ }^{13,17,21,23}$ In our study, all participants except six foreigners were Turkish. We observed different prevalences in seven different geographic regions of Turkey. This finding indicates that IGM may be observed in different frequencies within the same country as well. IGM generally affects young women between 17 and 42 years of age. The median age observed in our study was compatible with the literature. ${ }^{17,18,21}$ However, IGM may be observed in advanced ages such as 65 or 83 years as well. ${ }^{24}$ In agreement with a previous report, ${ }^{25}$ no significant difference was observed between the recurrence and nonrecurrence groups according to the mean age in our study.

Although possible effects of antipsychotic drugs and drugs increasing the prolactin level such as risperidone on IGM have been demonstrated, ${ }^{26}$ we did not observe any relationship between pain relievers, herbal, antihypertensive or antidiabetic medications and IGM or IGM recurrence.

The relationship between living environment and IGM is not well studied. In our study, $88 \%$ of the patients resided in a city. No relation was observed between the region of birth and place of living with the IGM recurrence. The findings observed in our study were found to be compatible with those in the literature. ${ }^{27}$ In our study, the educational statuses of the patients were mostly primary school, which was followed by high school. No significant difference was observed between the educational status and the IGM recurrence. In the study of Karanlik et al. ${ }^{17}$ investigating the efficacy of steroids plus surgery in IGM, no significant difference was observed between the groups with regard to the educational status. However, the relation between the educational status and recurrence has not been reported.

Although a possible connection between pregnancy, lactation and IGM recurrence has been reported, their role in IGM pathophysiology is not clear. Secretions, hormonal changes and inflammation during pregnancy and lactation may be effective in the pathophysiology of IGM. Localized autoimmune response against fat- and protein-rich secretions may underly the mechanism of prolactin in IGM pathogenesis. ${ }^{26,28-30}$ Furthermore, prolactin has been demonstrated to cause granulomatous lesions, immune response and non-caseating granulomas in both physiological and pathological actions. ${ }^{31}$ The incidence of prolactinoma among patients with IGM has been reported as $60-100 / 1000000 .^{32}$ Furthermore, a high prolactin level has been related to IGM recurrence. ${ }^{18}$ In one study, a history of pregnancy and lactating was observed in all patients with IGM except for two among 43 patients. ${ }^{25}$ In another study, granulomatous mastitis has been reported to be generally observed within several years following delivery. ${ }^{33}$ In the study of Al-Khaffaf et al., ${ }^{20}$ lactating was suggested to be in the history of patients with long-term IGM. Evaluation of patients with regard to the prolactin level and hypophysis adenoma is recommended in granulomatous mastitis. ${ }^{28}$ The findings observed in our study were found to be compatible with those in the literature.

Smoking is considered to be one of the possible aetiological factors for IGM with no definite conclusion. ${ }^{13,20,23}$ Our results suggested a significant relationship between smoking and IGM recurrence.

As oral contraceptives increase breast secretion, they are potential aetiological factors for IGM. Some studies demonstrate oral contraceptive use among patients with IGM as much as $42.1 \%$. However, no precise relationship has been demonstrated between oral contraceptive use and IGM. ${ }^{23}$ In our study, the oral contraceptive use was found to be $13 \%$ and no significant relationship was found with the IGM recurrence.

The hypothesis that autoimmunity may cause IGM has long been considered. The good response of IGM to steroid and immunosuppressive agents, the $\mathrm{T}$ lymphocyte dominance in immunohistochemical studies and the similarity of granulomatous mastitis to other autoimmune diseases, such as granulomatous thyroiditis and granulomatous prostatitis, form the basis for this theory. However, due to the absence of immunological abnormalities in some patients with granulomatous mastitis, this hypothesis has not been completely confirmed. The recurrence observed despite the immunosuppressive and steroid treatment in some of the patients with IGM has not rendered autoimmunity alone to be responsible in the aetiology. ${ }^{13}$ Furthermore, there is no sufficient evidence on the relation between autoimmunity and granulomatous mastitis. The role of autoimmune factors in the aetiology of IGM was not demonstrated in the study of Altıntoprak et al. ${ }^{14}$ In our study, autoimmune diseases were observed in only $3 \%$ of the patients with IGM. No relationship was observed between the IGM recurrence and autoimmune diseases considered within the group of chronic diseases.

There is a possible relationship between microbiological agents and granulomatous mastitis. Corynebacterium has particularly been blamed in the aetiology of granulomatous mastitis. Corynebacterium was first encountered in 34 of 68 patients with histopathologically diagnosed granulomatous mastitis by Taylor et al. ${ }^{34}$ However, as Corynebacterium was not isolated from all patients and its role in the aetiology of granulomatous mastitis is not yet clear. In our study, $32 \%$ of the patients had breast infections caused by different bacterial agents. A significant relationship was found between breast infection and the IGM recurrence. The infections observed in the patients were not the ones that were diagnosed at the time of the diagnosis of GM. These infections were in the history of the patients. In patients with a history of systemic bacterial infection, a significant relationship was observed between the IGM recurrence and systemic bacterial infection as well.

No correlation is observed between treatment methods and IGM recurrence in our study. Treatment choice and sequence of IGM is 
still debated. Currently, there is no universally accepted treatment strategy. ${ }^{13}$ Systemic corticosteroids and antibiotics are the most frequently used agents in the medical treatment of IGM. However, successful results have been reported with some agents, such as methotrexate, azathioprine, glucocorticoids, bromocriptine and colchicine $^{12}$ or combination with steroids. ${ }^{10}$ There are studies reporting lower recurrence rates with broad surgical resection, ${ }^{19}$ while others reporting an increased recurrence rate with surgical treatments.

There are certain limitations of our study: one of them was a short duration of patient follow-up; longer follow-up is needed to find out actual recurrence rate. As there were no enough records, the interval between the breastfeeding and the onset of IGM in our study was not evaluated. Collection data retrospectively is another limitation of the study; there is no universal approach to diagnosis and treatment of IGM among the study centres.

\section{Conclusion}

Our findings indicate that history of pregnancy, breastfeeding, breast infection and smoking are risk factors for IGM recurrence. As treatment methods examined in this study did not affect IGM recurrence, future research should focus on less invasive local treatment options and eliminate factors, such as breast infection and smoking.

\section{References}

1. Kessler E, Wolloch Y. Granulomatous mastitis: a lesion clinically simulating carcinoma. Am. J. Clin. Pathol. 1972; 58: 642-6.

2. Ozmen V, Cantürk Z, Celik V et al. Breast Disease. Ankara: Federation of Breast Diseases Society, Gunes Medical Publishing, 2012.

3. Centers for Disease Control and Prevention (CDC). Idiopathic granulomatous mastitis in Hispanic women - Indiana, 2006-2008. MMWR Morb. Mortal Wkly Rep. 2009; 58: 1317-21.

4. Ahmed R, Sultan F. Granulomatous mastitis: a review of 14 cases. J. Ayub Med. Coll. Abbottabad 2006; 18: 52-4.

5. Kayahan M, Kadioglu H, Muslumanoglu M. Management of patients with granulomatous mastitis: analysis of 31 cases. Breast Care (Basel) 2012; 7: 226-30.

6. Fazzio RT, Shah SS, Sandhu NP, Glazebrook KN. Idiopathic granulomatous mastitis: imaging update and review. Insights Imaging 2016; 7: 531-9.

7. Sripathi S, Ayachit A, Bala A, Kadavigere R, Kumar S. Idiopathic granulomatous mastitis: a diagnostic dilemma for the breast radiologist. Insights Imaging 2016; 7: 523-9.

8. Limaiem F, Korbi S, Tlili $\mathrm{T}$ et al. Idiopathic granulomatous mastitis mimicking breast cancer: report of two cases. Pathologica 2012; 104: $105-8$.

9. Oran ES, Gürdal SÖ, Yankol Y et al. Management of idiopathic granulomatous mastitis diagnosed by core biopsy: a retrospective multicenter study. Breast J. 2013; 19: 411-8.

10. Akbulut S, Yilmaz D, Bakir S. Methotrexate in the management of idiopathic granulomatous mastitis: review of 108 published cases and report of four cases. Breast J. 2011; 17: 661-8.

11. Bouton ME, Winton LM, Gandhi SG et al. Temporal resolution of idiopathic granulomatous mastitis with resumption of bromocriptine therapy for prolactinoma. Int. J. Surg. Case Rep. 2015; 10: 8-11.

12. Néel A, Hello M, Cottereau A et al. Long-term outcome in idiopathic granulomatous mastitis: a western multicentre study. QJM 2013; 106: 433-41.
13. Akcan $\mathrm{A}, \mathrm{Oz} \mathrm{AB}$, Dogan $\mathrm{S}$ et al. Idiopathic granulomatous mastitis: comparison of wide local excision with or without corticosteroid therapy. Breast Care (Basel) 2014; 9: 111-5.

14. Altintoprak F, Kivilcim T, Ozkan OV. Aetiology of idiopathic granulomatous mastitis. World J. Clin. Cases 2014; 2: 852-8.

15. Miltenburg DM, Speights VO Jr. Benign breast disease. Obstet. Gynecol. Clin. North Am. 2008; 35: 285-300.

16. Altintoprak F, Kivilcim T, Yalkin O, Uzunoglu Y, Kahyaoglu Z, Dilek ON. Topical steroids are effective in the treatment of idiopathic granulomatous mastitis. World J. Surg. 2015; 39: 2718-23.

17. Karanlik H, Ozgur I, Simsek S et al. Can steroids plus surgery become a first-line treatment of idiopathic granulomatous mastitis? Breast Care (Basel) 2014; 9: 338-42.

18. Aghajanzadeh M, Hassanzadeh R, Alizadeh Sefat S et al. Granulomatous mastitis: presentations, diagnosis, treatment and outcome in 206 patients from the north of Iran. Breast 2015; 24: 456-60.

19. Bani-Hani KE, Yaghan RJ, Matalka II, Shatnawi NJ. Idiopathic granulomatous mastitis: time to avoid unnecessary mastectomies. Breast $J$. 2004; 10: 318-22.

20. Al-Khaffaf B, Knox F, Bundred N. Idiopathic granulomatous mastitis: a 25-year experience. J. Am. Coll. Surg. 2008; 206: 269-73.

21. Korkut E, Akcay MN, Karadeniz E, Subasi ID, Gursan N. Granulomatous mastitis: a ten-year experience at a University Hospital. Eurasian J. Med. 2015; 47: 165-73.

22. Pandey TS, Mackinnon JC, Bressler L, Millar A, Marcus EE, Ganschow PS. Idiopathic granulomatous mastitis - a prospective study of 49 women and treatment outcomes with steroid therapy. Breast $J$. 2014; 20: 258-66.

23. Baslaim MM, Khayat HA, Al-Amoudi SA. Idiopathic granulomatous mastitis: a heterogeneous disease with variable clinical presentation. World J. Surg. 2007; 31: 1677-81.

24. Lai EC, Chan WC, Ma TK, Tang AP, Poon CS, Leong HT. The role of conservative treatment in idiopathic granulomatous mastitis. Breast $J$. 2005; 11: 454-6.

25. Omranipour R, Mohammadi SF, Samimi P. Idiopathic granulomatous lobular mastitis - report of 43 cases from Iran; introducing a preliminary clinical practice guideline. Breast Care (Basel) 2013; 8: 439-43.

26. Lin $\mathrm{CH}$, Hsu CW, Tsao TY, Chou J. Idiopathic granulomatous mastitis associated with risperidone-induced hyperprolactinemia. Diagn. Pathol. 2012; 7: 2.

27. Bouton ME, Jayaram L, O’Neill PJ, Hsu CH, Komenaka IK. Management of idiopathic granulomatous mastitis with observation. Am. J. Surg. 2015; 210: 258-62.

28. Nikolaev A, Blake CN, Carlson DL. Association between hyperprolactinemia and granulomatous mastitis. Breast J. 2016; 22: 224-31.

29. Rowe PH. Granulomatous mastitis associated with a pituitary prolactinoma. Br. J. Clin. Pract. 1984; 38: 32-4.

30. Cserni G, Szajki K. Granulomatous lobular mastitis following druginduced galactorrhea and blunt trauma. Breast J. 1999; 5: 398-403.

31. Lin CH, Ma H, Chung MT, Chou J. Granulomatous cutaneous lesions associated with risperidone-induced hyperprolactinemia in an amputated upper limb. Int. J. Dermatol. 2012; 51: 75-8.

32. Ciccarelli A, Daly AF, Beckers A. The epidemiology of prolactinomas. Pituitary 2005; 8: 3-6.

33. Hovanessian Larsen LJ, Peyvandi B, Klipfel N, Grant E, Iyengar G. Granulomatous lobular mastitis: imaging, diagnosis, and treatment. AJR Am. J. Roentgenol. 2009; 193: 574-81.

34. Taylor GB, Paviour SD, Musaad S, Jones WO, Holland DJ. A clinicopathological review of 34 cases of inflammatory breast disease showing an association between corynebacteria infection and granulomatous mastitis. Pathology 2003; 35: 109-19. 